\title{
KEEFEKTIFAN PENGGUNAAN MEDIA PEMBELAJARAN BERBASIS KANTONG BILANGAN UNTUK MENINGKATKAN HASIL BELAJAR MATEMATIKA SISWA KELAS I SD
}

\author{
Sri Kundarsih ${ }^{1}$, Su'ad $^{2}$, Santoso $^{3}$ \\ 1,2,3 Universitas Muria Kudus, Indonesia \\ 1srikundarsih@gmail.com, ${ }^{2}$ sua'ad@umk.ac.id, ${ }^{3}$ santoso@umk.ac.id
}

\begin{abstract}
ABSTRAK
Latar belakang masalah dalam penelitian ini adalah rendahnya hasil belajar siswa kelas 1 pada pembelajaran matematika materi penjumlahan dan pengurangan. Faktor- faktor yang menyebabkan hasil belajar matematika masih rendah salah satunya adalah masih kurangnya penggunaan media yang menarik dan menunjang proses pembelajaran. Tujuan penelitian ini adalah Menganalisis efektivitas media pembelajaran kontekstual berbasis kantong bilangan untuk meningkatkan hasil belajar matematika materi penjumlahan dan pengurangan siswa kelas 1 SD. Teknik pengumpulan data yang digunakan adalah observasi, angket dan Tes tetulis. Instrumen penelitian berupa tes dan angket. Sampel penelitian ini dilakukan dengan Purpose sampling. data Aanalisis data meliputi deskripsi data, uji prasyarat analisis, dan uji hipotesis dengan menggunakan uji t. Hasil uji efektivitas melalui uji coba produk pada independent Paired Sampel t test, Nilai rata-rata pre test sebesar 42.02 dan Nilai rata-rata posttest sebesar 78.81 menunjukkan adanya peningkatan hasil belajar siswa kelas 1 di SD setelah menggunakan media pembelajaran kantong bilangan.
\end{abstract}

Kata Kunci: media kantong bilangan, hasil belajar, matematika

\section{THE EFFECTIVENESS OF USING NUMBER BAG-BASED LEARNING MEDIA TO INCREASE STUDENTS' MATHEMATICS LEARNING OUTCOMES AT GRADE I ELEMENTARY SCHOOL}

\begin{abstract}
The background of the problem in this study was the students' low learning outcomes in mathematics learning, especially in the addition and subtraction materials. One factor causing this low learning outcomes was the lack of using attractive media to support the learning process. The purpose of this study was to analyze the effectiveness of number bag-based contextual learning media to improve the students' mathematics learning outcomes for the addition and subtraction materials at grade 1 elementary school. The data were collected through observation, questionnaires, and written tests. The research instruments were tests and questionnaires. The sample of this research was selected by using purposive sampling. Then, the techniques of data analysis included data descriptions, analysis prerequisite tests, and hypothesis testing using the t test. The effectiveness test was conducted through product trials on the independent Paired Sample t test. The result of this test obtained that the pre-test average value was 42.02 and the post-test mean score was 78.81. Thus, utilizing number bag-based learning media increased the students' learning outcomes at grade 1 of elementary school.
\end{abstract}

Keywords: number bag media, learning outcomes, mathematics

\begin{tabular}{|c|c|c|}
\hline Submitted & Accepted & Published \\
\hline 24 Februari 2021 & 05 Januari 2022 & 28 Januari 2022 \\
\hline
\end{tabular}

\begin{tabular}{|l|c|c|}
\hline Citation & $:$ & $\begin{array}{r}\text { Kundarsih, S., Su'ad, S., \& Santoso, S. (2021). Keefektifan Penggunaan Media Pembelajaran Berbasis Kantong Bilangan } \\
\text { untuk Meningkatkan Hasil Belajar Matematika Siswa Kelas I SD. Jurnal PAJAR (Pendidikan dan Pengajaran), } \\
6(1), 140-147 . \text { DOI : http://dx.doi.org/10.33578/pjr.v6i1.8339. }\end{array}$ \\
\hline
\end{tabular}

\section{PENDAHULUAN}

Matematika merupakan disiplin ilmu bersifat universal yang mendasari perkembangan teknologi modern. Matematika mempunyai peranan penting dalam berbagai disiplin ilmu dan membangun daya pikir manusia. Dalam kehidupan sehari-hari manusia tidak bisa lepas dari permasalahan yang berhubungan dengan matematika. setiap orang pasti akan menggunakan matematika baik itu penjumlahan, pengurangan, perkalian maupun pembagian. Menurut Rostina Sundayana (2013:25) menjelaskan bahwa, "Konsep-konsep dalam matematika itu bersifat abstrak, sedangkan pada umumnya siswa sekolah dasar (SD) berpikir dari hal-hal yang konkrit menuju hal-hal yang abstrak, maka salah satu jembatan agar siswa mampu berpikir abstrak tentang matematika adalah menggunakan media 
Pendidikan dan alat peraga (media)."aktivitas dan kreatifitas peserta didik

Namun pada pelaksanaannya proses pembelajaran matematika pada siswa kelas 1 materi penjumlahan dan pengurangan di sekolah belum menggunakan media pembelajaran yang konkrit sehingga siswa masih kesulitan dalam memahami materi yang disampaikan oleh guru. Dalam menyampaikan materi pelajaran guru hanya menggunakan metode ceramah saja dan pembelajaran berpusat pada guru. Hal tersebut membuat siswa menjadi bosan dan pembelajaran menjadi kurang bermakna bagi siswa. Sehingga berpengaruh terhadap hasil belajar siswa

Hal tersebut dapat terlihat berdasarkan hasil observasi dan wawancara dengan guru kelas I di beberapa SDN yang ada di Dabin I kecamatan Mijen Kabupaten Demak, menunjukkan bahwa hasil belajar Matematika siswa materi penjumlahan dan pengurangan belum seperti yang diharapkan, yaitu belum memenuhi kriteria ketuntasan minimal (KKM) yang ditetapkan oleh sekolah yaitu 70 .

Dibandingkan dengan mata pelajaran lain, prestasi siswa dalam mata pelajaran matematika masih relatif rendah. Faktor- faktor yang menyebabkan prestasi belajar matematika masih rendah salah satunya adalah masih kurangnya penggunaan media yang menarik dan menunjang proses pembelajaran. Dalam pengajaran matematika diharapkan guru mampu menciptakan dan mempergunakan media yang menarik bagi siswa. Dengan media yang tepat dan menarik diharapkan memiliki dampak positif pada siswa tentang apa yang dipelajari akan lebih lama bertahan dalam benak siswa. Walaupun siswa termasuk dalam kategori mempunyai kemampuan yang pandai, namun apabila dalam pembelajaran guru tidak menggunakan media yang mampu merangsang pemikiran siswa maka prestasi belajar siswa tidak akan sebagus dibanding dengan pembelajaran yang didukung media yang tepat . Pada umumnya, pengajaran yang sering disodorkan oleh guru hanya berupa teori - teori untuk dihafal kemudian diuji. Padahal, belajar dengan cara menghafal sungguh mematikan kreativitas otak untuk berpikir. Guru mendominasi pembelajaran dengan penjelasan tanpa.
Media pembelajaran yang tepat sangat dibutuhkan dalam proses belajar mengajar karena dapat menentukan keberhasilan siswa dalam belajar. Siswa diharapkan memahami materi secara mendalam dengan dipergunakannya media pembelajaran karena dapat berdampak pada ingatan siswa tentang materi yang telah diajarkan. Setiap konsep akan lebih mudah untuk dipahami dan diingat apabila disajikan dengan media yang tepat. Salah satu indikator proses pembelajaran yang ideal adalah dengan diperunakannya media pembelajaran yang mampu meningkatkan hasil belajar siswa. Kesalahan menggunakan media, dapat menghambat tercapainya tujuan pendidikan yang diinginkan. Untuk mengatasi permasalahan tersebut, seorang guru dituntut untuk mendesain suatu media.

Penggunaan media yang tepat dapat dapat meningkatkan minat belajar siswa. Salah satu media dalam pembelajaran matematika yang dapat menunjang proses pembelajaran yaitu media pembelajaran Kantong Bilangan. Media pembelajaran Kantong Bilangan merupakan suatu media pembelajaran yang berisi kotak - kotak yang bisa dipergunakan untuk mengetahui nilai tempat suatu bilangan dan mempermudah siswa untuk melakukan operasi hitung penjumlahan dan pengurangan. Melalui media ini, akan tercipta pemahaman yang mendalam bagi siswa tentang materi yang dipelajarinya yaitu operasi hitung penjumlahan dan pengurangan. Suasana belajar yang ditimbulkan akan lebih terasa menyenangkan karena siswa belajar dengan dibantu alat yang bisa membantu mereka menunjukkan nilai tempat suatu bilangan serta memudahkan untuk melakukan operasi hitung, sehingga meningkatkan pemahaman materi dan lebih jauh yaitu hasil belajar siswa. Dengan berpijak pada beberapa persoalan yang ada, maka hal itulah yang mendorong bagi peneliti untuk melakukan penelitian yang membahas tentang penerapan media pembelajaran Kantong Bilangan yang diharapkan hasil belajar siswa dalam belajar matematika dapat meningkat.

\section{KAJIAN TEORETIS}

Rusman, dkk (2012: 170) mengemukakan media pembelajaran merupakan suatu teknologi pembawa pesan yang dapat digunakan untuk 
keperluan pembelajaran dan media pembelajaran merupakan sarana fisik untuk menyampaikan materi pelajaran. Dina Indriana (2011: 15) menjelaskan media pembelajaran merupakan salah satu alat komunikasi dalam proses pembelajaran. Arsyad (2017: 19) menyatakan bahwa " salah satu fungsi utama media pembelajaran adalah sebagai alat bantu mengajar yang turut mempengaruhi iklim, kondisi, dan lingkungan belajar yang ditata dan diciptakan guru

Kemp dan Dayton dalam Arsyad, (2017: 23), media pembelajaran dapat memenuhi tiga fungsi utama apabila media itu digunakan untuk perorangan, kelompok, atau kelompok yang besar jumlahnya, yaitu dalam hal (1) memotivasi minat atau tindakan, (2) menyajikan informasi, dan (3) memberi instruksi. Untuk memenuhi fungsi motivasi, media pembelajaran dapat direalisasikan dengan teknik drama atau hiburan. Untuk tujuan informasi, media pembelajaran dapat digunakan dalam rangka penyajian informasi di hadapan sekelompok siswa. Isi dan bentuk penyajian bersifat sangat umum, berfungsi sebagai pengantar, ringkasan laporan, atau pengetahuan latar belakang. Sedangkan untuk tujuan instruksi informasi yang terdapat dalam media harus melibatkan siswa baik dalam benak atau mental maupun dalam bentuk aktivitas yang nyata sehingga pembelajaran dapat terjadi

Purwanto (2013:51) mengatakan bahwa hasil belajar adalah perwujudan kemampuan akibat perubahan perilaku yang dilakukan oleh usaha pendidikan yang menyangkut domain kognitif, afektif, dan psikomotorik. Menurut Anni (2004:4) hasil belajar merupakan perubahan perilaku yang diperoleh pembelajar setelah mengalami aktivitas belajar. Perolehan apek-aspek perubahan perilaku tersebut tergantung pada apa yang dipelajari oleh pembelajar.Menurut Nana Sudjana (2009:3) mendefinisikan hasil belajar siswa pada hakikatnya adalah perubahan tingkah laku sebagai hasil belajar yang mencakup bidang kognitif, afektif, dan psikomotorik

Amini, \& Efrina (2019). Media Kantong Bilangan dalam Meningkatkan Konsep Nilai Tempat pada Anak Berkesulitan Belajar. Berdasarkan analisis data tersebut menunjukkan bahwa media kantong bilangan mampu meningkatkan konsep nilai tempat pada anak berkesulitan belajar kelas III SDN 27 Olo Ladang Padang. Lestari, E. D., Handayani, T., \& Sulistiani, S. (2019). Pengunaan Media Kantong Bilangan untuk Meningkatkan Kemampuan siswa dalam Materi Pengurangan pada Siswa Kelas 1-A SDN Tlogomas 2 Kota Malang. Hasil bahwa dengan menggunakan media kantong bilangan efektif meningkatkan kemampuan menentukan nilai tempat pada siswa berkesulitan belajar

\section{METODE PENELITIAN}

Desain penelitian ini berupa Quasi eksperimental dengan bentuk nonequivalent control group design (desain pretest-posttest kelompok control tanpa random), Sugiono (2017:116). Dalam disain ini subjek kelompok tidak dilakukan secara acak, misalnya kelas eksperimen disuatu kelas tertentu dengan siswa yang telah ada atau sebagaimana adanya. Instrumen penelitian berupa angket dan tes. Sampael penelitian adalah 4 SD yaitu dari kelas 1 SD N Rejosari 1, dan keas 1 SD N Ngegot., SDN Tanggul dan SDN geneng 3. .Pemilihan sampling dalam penelitian ini adalahdengan teknik cluster sampling Teknik pengumpulan data yang digunakan adalah observasi, angket dan Tes tetulis. .Aanalisis data meliputi deskripsi data, uji prasyarat analisis, dan uji hipotesis dengan menggunakan uji t.

\section{HASIL DAN PEMBAHASAN}

Hasil penelitian didapat data statistik deskriptif untuk instrumen tes dan angket adalah 
Tabel 1. Deskripsi Data Tes Statistics

\begin{tabular}{|c|c|c|c|}
\hline & & Nilai pre test & nilai post tes \\
\hline \multirow[t]{2}{*}{$\mathrm{N}$} & Valid & 115 & 115 \\
\hline & Missing & 0 & 0 \\
\hline \multicolumn{2}{|c|}{ Mean } & 42.02 & 78.81 \\
\hline \multicolumn{2}{|c|}{ Std. Deviation } & 17.157 & 16.829 \\
\hline \multicolumn{2}{|c|}{ Minimum } & 12 & 37 \\
\hline \multicolumn{2}{|c|}{ Maximum } & 75 & 100 \\
\hline \multicolumn{2}{|c|}{ Sum } & 4832 & 9063 \\
\hline
\end{tabular}

Berdasarkan tabel diatas maka terdapat peningkata nilai rata-rata pre tes dan post test. Nilai rata-rata pre test sebesar 42.02 dan Nilai rata-rata post test sebesar 78.81 .

\section{Uji N Gain}

Hasil uji gain dilakukan dengan bantuan SPSS. adapun hasil uji N Gain pada data hasil uji coba produk secara luas adalah sebagai berikut:

\section{Tabel 2. Hasil Uji N Gain}

\begin{tabular}{clc}
\hline No & \multicolumn{1}{c}{ Nilai } & Kelas Eksperimen \\
\hline 1 & Mean & 58.7284 \\
2 & Minimum & -52.00 \\
3 & Maximum & 100 \\
4 & N-Gain & 0,587 \\
5 & Kriteria & Sedang \\
5 & N-Gain \% & 58,7 \\
7 & Tafsiran & Cukup efektif \\
\hline
\end{tabular}

Berdasarkan data tersebut, hasil perhitungan gain adalah kelas

1. diperoleh rata-rata NGain sebesar 58.7284 dan diperoleh nilai N-gain 0.677 Artinya kelas eksperimen mengalami peningkatan hasil belajar dengan kategori sedang karena $0.7>\mathrm{g}$ $\geq 0.3$.

2. Nilai $\mathrm{N}$-Gain $\%$ sebesar 58.7 yang ditafsirkan bawa pembelajaran matematika dengan menggunakan media pembelajran berbasis kantong bilangan cukup efektif digunakan untuk meningkatkan hasil belajar siswa kelas I SD matematika pada materi penjumlahan dan pengurangan.

\section{Uji t}

Uji t pada uji coba secara luas menggunakan independent Paired Sampel t test. Berikut ini hasil uji t adalah :

Tabel 3 . Uji Paired Samples Test Paired Samples Statistics

\begin{tabular}{llrrrr}
\hline & & Mean & N & Std. Deviation & Std. Error Mean \\
\hline Pair 1 & Nilsi Pre Tes & 42.02 & 115 & 17.157 & 1.600 \\
& Nilsi Post Test & 78.81 & 115 & 16.829 & 1.569 \\
\hline
\end{tabular}


Paired Samples Test

\begin{tabular}{|c|c|c|c|c|c|c|c|c|}
\hline & \multicolumn{5}{|c|}{ Paired Differences } & \multirow[b]{3}{*}{$\mathrm{T}$} & \multirow[b]{3}{*}{ Df } & \multirow{3}{*}{$\begin{array}{l}\text { Sig. }(2- \\
\text { tailed) }\end{array}$} \\
\hline & \multirow[b]{2}{*}{ Mean } & \multirow{2}{*}{$\begin{array}{c}\text { Std. } \\
\text { Deviation }\end{array}$} & \multicolumn{3}{|c|}{$\begin{array}{l}95 \% \text { Confidence Interval } \\
\text { Std. Error } \quad \text { of the Difference }\end{array}$} & & & \\
\hline & & & Mean & Lower & Upper & & & \\
\hline $\begin{array}{ll}\text { Pair } & \text { Nilsi Pre Tes - } \\
1 & \text { Nilsi Post Test }\end{array}$ & -36.791 & 25.051 & 2.336 & -41.419 & -32.164 & -15.750 & 114 & .000. \\
\hline
\end{tabular}

Hasil perhitungan pada table 3 diketahui:

1. Nilai rata-rata untuk terdapat perbedaan dari pre test sebesar 42.02 dan post test sebesar 78.81

2. t hitung sebesar 15.750 , karena nilai post tst lenih besar daripada pre test sehingga thitung menjadi negarif. Maka t hitung atau 15.750 sedangkan $\mathrm{t}$ tabel dengan $\mathrm{df}=114$ sebesar 3.924 maka atau $15.750>3.924$. Karena thitung > ttabel, maka H0 ditolak dan $\mathrm{Ha}$ diterima

\section{Pembahasan}

Berdasarkan hasil olah data pada uji coba prudiuk diperoleh hasil bahwa nilai pre test pada kelas kontrol dan kelas eksperimen mempunyai nilai rata-rata yang hampir sama, sehingga menunjukan bahwa kemampuan kedua kelas adalah sama atau seimbang. Sedangkan nilai post test kelas eksperimen lebih tinggi dari pada kelas kontrol. Pada kelas kontrol pembelajran tanpa media pembelajran kantong bilangan dan pada kelas eksperimen menggunakan media pembelajran kantong bilang. Hal ini berarti penggunaan media pembelajaran berbasis kantong bilangan mampun meningkatkan hasil belajar siswa.

Hasil uji $N$-Gain diperoleh rata-rata NGain sebesar 58.7 dan N-Gain \% sebesar 58.7 yang ditafsirkan cukup efektif, dari hasil analisis $\mathrm{N}$ Gain maka baik data uji coba secara terbatas maupun uji coba secara luas menunjukan bahwa media pembaljaran berbasis kantong bilangan cukup efektif digunakan untuk meningkatkan hasil belajar matematika materi penjumlahan dan pengurangan.

Hasil ini sesuai dengan pendapat Menurut (Lamatenggo, 2010:141) menyatakan ada beberapa fungsi media pembelajaran dalam bidang matematika di atantaranya adalah sebagai berikut: 1) Dengan adanya media pembelajaran anak-anak akan lebih banyak mengikuti. pelajaran matematika dengan gembira sehingga minatnya dalam belajar matematika akan semakin besar, anak akan sengang terangsang, tertarik dan bersikap positif terhadap pembelajaran matematika. 2) Dengan disajikan konsep abstrak matematika dalam bentuk konkret, maka siswa pada tingkat-tingkat yang lebih rendah akan lebih mudah memahami dan mengerti.3) Media pembelajaran dapat membantu daya tilik ruang, karena anak tidak dapat membayangkan bentukbentuk geometri ruang sehingga gambar akan benda-benda nyata menjadi media pemahaman tentang ruang., 4) Anak akan menyadari hubungan anatara pembelajaran dengan benda-benda yang ada di sekitarnya, atau anatara ilmu dengan alam sekitarnya dan masyarakat. Konsep-konsep abstrak yang tersajikan dalam bentuk kokret yaitu dalam bentuk model matematika dapat dijadikan sebagai objek penelitian dan dapat pula dijadikan alat untuk penelitian ide-ide dan relasi-relasi baru.

Kelebihan penggunaan kantong bilangan menurut Martianti Narore dalam Siti Zulaichah 2014 yaitu menkonkretkan konsep yang dipelajari. Kantong bilangan merupakan media 3 dimensi yang memberikan gambaran proses konkret dalam pembelajaran, gambaran nyata ini diperoleh dari pengoperasian yang dilakukan menggunakan kantong-kantong dan sedotan yang dijadikan bentuk konkret dari simbol matematika. Berdasarkan hal tersebut diharapkan anak akan lebih mudah dalam memahami konsep. Media kantong bilangan dibuat berdasarkan keefektifan media, salah satunya yaitu media kantong bilangan dibuat berdasarkan konsep nyata pengoperasian penjumlahan. Sedangkan menurut Dwi Yuniarto 2012 menyampaikan kelebihan penggunaan media 
kantong bilangan sebagai berikut : a) Membantu guru untuk menyampaikan materi pembelajaran dengan lebih menarik. b) Membantu guru untuk bisa menyampaikan suatu konsep pembelajaran yang abstrak menjadi sebuah situasi yang nyata. c) Memantapkan pengetahuan siswa dalam memahami nilai tempat suatu bilangan. d) Membantu siswa untuk menyelesaikan masalah operasi hitung dengan cara yang sistematis.

Berdasarkan hasil uji t $t$ hitung sebesar 15.750 sedangkan $\mathrm{t}$ tabel dengan $\mathrm{df}=135$ sebesar 3.924 maka $15.750>3,924$. Karena $\mathrm{t}_{\text {hitung }}>\mathrm{t}_{\text {tabel, }}$ maka H0 ditolak dan Ha diterima artinya terdapat terdapat peningkatan pada penggunaan media pembelajaran kontekstual kantong bilangan terhadap hasil belajar siswa kelas 1 pada materi penjumlahan dan pengurangan. Menurut Heruman 2007:19 menyebutkan fungsi penggunaan kantong bilangan sebagai berikut : 1) Sebagai media dalam pembelajaran matematika, khususnya pada operasi hitung matematika, 2) Sebagai salah satu sumber belajar matematika pada operasi bilangan, 3) Sebagai motivasi belajar bagi siswa karena ditampilkan 22 dengan media yang sederhana tetapi menarik. Kantong bilangan merupakan media 3 dimensi yang memberikan gambaran proses konkret dalam pembelajaran, gambaran nyata ini diperoleh dari pengoperasian yang dilakukan menggunakan kantong-kantong dan sedotan yang dijadikan bentuk konkret dari simbol matematika. Dengan gambaran nyata dari media kantong bilangan diharapkan mampu mempengaruhi kondisi anak sehingga mampu meningkatkan motivasi anak dan pemahaman anak. Perpaduan penjelasan di atas diharapkan mampu memudahkan anak dalam memahami konsep penjumlahan secara bersusun dan pada gilirannya dapat meningkatkan hasil belajar matematika siswa tentang penjumlahan secara bersusun.

Berdasarkan hasil penelitian dan pembahasan maka dapat disimpulkan bahwa pembelajaran tentang pembelajran matematika menggunakan media pembelajaran kontekstual kantong bilangan. Artinya hipotesis yang menyatakan ada peningkatan tentang pembelajaran matematika menggunakan media pembelajaran kontekstual kantong bilangan terhadap hasil belajar siswa kelas 1 materi penjumlahan dan pengurangan terbukti

\section{SIMPULAN DAN REKOMENDASI}

Berdasarkan hasil penelitian dan pembahasan dapat disimpulakan Media pembelajaran kontekstual berbasis kantong bilangan cukup efektif digunakan untuk meningkatkan hasil belajar siswa kelas 1 pada pelajaran matematika materi penjumlahan dan pengurangan. Hal ini dibuktikan dengan nilai nilai $\mathrm{N}$-Gain baik data uji coba terbatas maupun secar luas ditafsirkan cukup efektif. Hasil uji t dengan Nilai $t$ hitung sebesar 5.014 Nilai $t$ tabel 2.0003 maka nilai $t$ hitung $>t$ tabel $(5.014>2.0003)$ dan uji $t$ secar luas sebesar $15.750>3.924$ artinya ada peningkatan yang signifikan hasil hasil belajar siswa kelas 1 materi penjumlahan dan pengurangan bilangan dengan pembelajaran menggunakan media pembelajaran kontekstual berbasis media kantong bilangan

Saran yang diberikan penulis adalah 1) Guru kelas 1 supaya menggunakan media pembelajaran kantong bilangan untuk pembelajaran matematika materi penjumlahan dan pengurangan agar hasil belajar siswa dapat meningkat.2) Penggunaan media pembelajaran sebagai alat bantu mengajar perlu di kembangkan agar dapat menunjang penggunaan metode mengajar yang digunakan dalam pembelajaran, dikarenakan media merupakan alat bantu yang dapat memperjelas, mempermudah, mempercepat penyampaian pesan atau materi pelajaran sehingga dapat meningkatkan mutu pendidikan

\section{DAFTAR PUSTAKA}

Anni, C. T. (2004). Psikologi Belajar. Semarang: UPT UNNES Press.

Amini, A., \& Efrina, E. (2019). Media Kantong Bilangan dalam Meningkatkan Konsep Nilai Tempat pada Anak Berkesulitan Belajar. Jurnal Penelitian Pendidikan Khusus, 7(2), 49-54.

Arikunto, S. (2010). Prosedur Penelitian Suatu Pendekatan Praktik. Jakarta: PT Rineka Jaya. 
Badar, A., \& Ibnu, T. (2017). Mendesain Model Pembelajaran Inovatif, progresif, dan kontekstual. Jakarta: Kencana.

Batubara, H. H. (2015). Pengembangan Media Pembelajaran Interaktif pada Materi Operasi Bilangan Bulat. MUALLIMUNA: Jurnal Madrasah Ibtidaiyah, 1(1), 1-12

Bovee, C. (1997). Business Communication Today. New York :Prentice Hall.

Djamarah, S. B., dan Aswan, Z. (2013). Strategi Belajar Mengajar. Jakarta: Rineka Cipta.

Febriyanto, B., Haryanti, Y. D., \& Komalasari, O. (2018). Peningkatan pemahaman konsep matematis melalui penggunaan media kantong bergambar pada materi perkalian bilangan di Kelas II Sekolah Dasar. Jurnal Cakrawala Pendas, 4(2), 32-44.

Hamalik, O. (2015). Proses Belajar Mengajar. Jakarta: PT Bumi Aksara.

Istirani. (2012). 58 Model Pembelajaran Innovatif. Medan: Media Persada.

Jalaliyah, K., Muhammad, H, dan Khoirul, A. (2019). Penerapan Media Kantong Bilangan Untuk Meningkatkan Hasil Belajar Siswa Dalam Penjumlahan Bilangan Pada Tema "Benda, Hewan dan Tanaman di Sekitarku” Kelas 1 MI Nurul Yaqin Gading Probolinggo. JPMI: Jurnal Pendidikan Madrasah Ibtidaiyah, 1(3), 11-16.

Kustandi, C. (2011). Media Pembelajaran Manual dan Digital. Bogor: Ghalia Indonesia.

Jalaliyah, K., Hanief, M., \& Asfiyak, K. (2019). Penerapan media kantong bilangan untuk meningkatkan hasil belajar siswa dalam penjumlahan bilangan pada tema "Benda, hewan dan tanaman di sektarku" Kelas 1 MI Nurul Yaqin Gading.. JPMI: Jurnal Pendidikan Madrasah Ibtidaiyah, 1(3), 916.

Johnson, B. E. (2014). Contextual Teaching \& Learning Menjadikan Kegiatan Belajar Mengasyikkan dan Bermakna. Bandung : Kaifa.

Hildayanti, N. (2014). Perbandingan Efektifitas antara Media Kantong dengan Media Kotak untuk Meningkatkan Kemampuan Mengenal Nilai Tempat bagi Anak
Kesulitan Belajar. Jurnal Penelitian Pendidikan Khusus, 3(3), 20-45.

Lestari, E. D., Handayani, T., \& Sulistiani, S. (2019). Pengunaan Media Kantong Bilangan untuk Meningkatkan Kemampuan siswa dalam Materi Pengurangan pada Siswa Kelas 1-A SDN Tlogomas 2 Kota Malang. . Taman Cendekia: Jurnal Pendidikan Ke-SDan, 3(1), 283-289

Nana, S. (2009). Penilaian Hasil Belajar. Bandung: Rossda Karya.

Nawa, A. (2018). Contextual Teaching and Learning (CTL) Approach through REACT Strategies on Improving the Students' Critical Thinking in Writing. International Journal of Applied Management Science, 5(5), 1-5.

Piaget, J., \& Barbel, I. (2010). Psikologi Anak,Terj. Miftahul Jannah, Yogyakarta: Pustaka Pelajar.

Prastia, I. E. (2019). Efektivitas Media Kantong Bilangan Terhadap pengenalan Konsep Bilangan 1-10 pada anak Tuna Grahita Ringan. hasil bahwa media kantong bilangan efektif terhadap pengenalan konsep bilangan 1-10 pada anak tunagrahita ringan kelas I SDLB YapenasUnit II Sleman. WIDIA ORTODIDAKTIKA, 8(4), 400-405.

Purwanto. (2011). Evaluasi Hasil Belajar. Yogyakarta: Pustaka Pelajar.

Ruseffendi, E.T, dkk. (1992). Pendidikan Matematika 3,Jakarta : Depdikbud.

Sanjaya, W. (2012). Strategi Pembelajaran Berorientasi Standar Proses Pendidikan. Jakarta: Kencana.

Santoso, E. (2017). Penggunaan Model Pembelajaran Kontekstual Untuk Meningkatkan Kemampuan Pemahaman Matematika Siswa Sekolah Dasar (Studi pada siswa kelas V SDN Sukarasa II Kecamatan Samarang Kabupaten Garut Tahun pelajaran 2014-2015). Jurnal Cakrawala Pendas, 3(1),16-29.

Slameto. (2010). Belajar dan Faktor-faktor yang Mempengaruhinya. Jakarta: PT Rineka Cipta. 
Sugiyono. (2019). Metode Penelitian \& Pengembangan: Research and Development. Bandung: Alfabeta.

Sukmadinata, N. S. (2010). Metode Penelitian Pendidikan. Bandung: Remaja Rosdakarya.

Suprijono, A. (2009). Cooperative Learning Teori dan Aplikasi PAIKEM. Yogyakarta: Pustaka Belajar.

Suratina, T. (2001). Anak Super Normal dan Program Pendidikannya. Jakata: Bina Aksara.

Trianto. (2010). Model Pembelajaran Terpadu; Konsep, Strategi, dan Implementasinya dalam Kurikulum Tingkat Satuan Pendidikan (KTSP). Jakarta: Bumi Aksara.

Udin, W. (2007). Teori Belajar dan Pembelajar. Jakarta: Pusat Penerbitan Universitas terbuka.

Undang-Undang Nomor 20 Tahun 2003 tentang Sistem Pendidikan Nasional. Jakarta.

Wahyuningtyas, D.T. dan Suastika, I K. (2016). Developing Learning Modules of Numbers for Primary School Students Using Contextual Teaching and Learning Approach. Jurnal Pendidikan Dasar Indonesia, 1(2). 33-36. 